\title{
Ángel Palerm: reflexiones sobre el impacto de su trabajo de campo y docencia
}

\author{
Robert V. Kemper
}

\section{INTRODUCCIÓN}

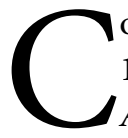

onocí a Ángel Palerm en noviembre de 1969, al final de la Reunión Anual de la Asociación Americana de Antropología, en el aeropuerto de Nueva Orleans, cuando estaba por salir de la ciudad. Fue un enorme placer encontrarlo. Como estudiante de George Foster - quien fungió como director del Instituto de Antropología Social en Washington, D. C., antes de ser profesor de antropología en la Universidad de California en Berkeley-, estaba al tanto del trabajo que Palerm había desarrollado al lado de Isabel Kelly entre los totonacos del Tajín en las décadas de 1940 y 1950 (Kelly y Palerm, 1952). Nuestra breve plática sirvió para que él se enterara de mi proyecto de trabajo de campo entre los migrantes de Tzintzuntzan en la ciudad de México, así como de mis más amplios intereses en los temas de urbanización y migración. Se percató de inmediato de que pasaba la mayor parte de mi tiempo en el Distrito Federal y antes de abordar el avión me invitó a impartir un seminario de antropología urbana en la Universidad Iberoamericana
(Ibero) en el semestre de primavera de 1970 que se avecinaba. ${ }^{1}$

Aquella primera experiencia docente en la Ibero - entonces ubicada a corta distancia de la estación Taxqueña del Metro- fue el inicio de una larga relación. Volví a México en 1980 gracias a una beca de la Fundación Fulbright y un permiso de investigación de un año otorgado por la Universidad Metodista del Sur (Southern Methodist University, SMU), donde trabajo desde 1972 y como profesor asociado desde 1977. Aunque no fue requisito de la beca, me pareció correcto ofrecer mi servicio como profesor a la Ibero, aún situada en el sur de la

\footnotetext{
${ }^{1}$ Creo que fue el primer seminario sobre antropología urbana impartido en México. Entre los estudiantes estaba Larissa Adler Lomnitz, quien necesitaba una materia más para completar los cursos de su programa de doctorado antes de entregar su disertación sobre la gente de Cerrada del Cóndor en la ciudad de México (Adler, 1975). A lo largo de su brillante carrera, Adler llegó a ser una de las más reconocidas antropólogas en México. En 2006 recibió el Premio Nacional de Ciencias y Artes en el área de historia, ciencias sociales y filosofía, y en 2010 presentó la Conferencia Magistral Anual para Antropología Cultural "George y Mary Foster" en la Universidad Metodista del Sur.
}

\section{Ángel Palerm: Reflections on the Impact of his Field Work and Teaching}

Robert V. Kemper: Southern Methodist University, Dallas, Texas, Estados Unidos 
ciudad. Resultó que impartí no sólo el seminario sobre antropología urbana durante el semestre de primavera de 1980, sino también la materia de metodología de investigación, a la que asistieron estudiantes que trabajaban en o cerca de la ciudad de México. ${ }^{2}$ También obtuve una pequeña beca de la oficina de la Fundación Ford en la capital, que me permitió incorporar a dos estudiantes de la Ibero en mi equipo de trabajo del Proyecto Tzintzuntzan, uno en la ciudad de México y otro en Tijuana y California. ${ }^{3}$

Incluso después de su muerte en junio de 1980, Palerm me brindó una oportunidad adicional de trabajar con estudiantes de antropología en esa universidad, ya que hasta la fecha de su fallecimiento se desempeñaba como coordinador del comité de tesis de una alumna que había asistido a mis clases aquella primavera. Me ofrecieron - y aceptéasesorar a esa estudiante en su trabajo de campo y en su momento fui el presidente de su comité de tesis. ${ }^{4}$ Gracias a las oportunidades que me ofreció Ángel Palerm durante mi primera década de trabajo en
México, logré relacionarme con importantes antropólogos, entre ellos Larissa Adler Lomnitz, Elio Masferrer Kan, Víctor Clark Alfaro y Janet Long de Solís. Con el paso de los años llegué a apreciar cada vez más que Ángel Palerm abriera puertas que nos permitieron, a mí y a otros jóvenes académicos extranjeros que llevaban a cabo investigaciones en México, participar en la comunidad antropológica de México y avanzar en nuestras carreras.

\section{GEORGE FOSTER E ISABEL KELLY}

Conocí a Isabel Kelly en la ciudad de México en abril de 1969, cuando George Foster, mi mentor en la Universidad de California en Berkeley, me pidió que la llevara a su casa en Tepepan al terminar el Congreso de la Sociedad de Antropología Aplicada. En compañía de Foster, su esposa Mary y mi esposa Sandra, manejé la considerable distancia desde la colonia Cuauhtémoc en el sector central-oeste de la metrópoli hasta Tepepan en el extremo sureste. Quedé asombrado al ver su casa, adornada con muebles, alfombras y muestras de arte folklórico que parecían aptos para exponerse en un museo, pero sobre todo por su impresionante biblioteca personal, que llenaba a tope lo que era la casa original de aquella amplia propiedad. Animado por George Foster, me encontré con Isabel Kelly durante mis frecuentes viajes a la ciudad de México durante los 12 años posteriores. Kelly falleció en diciembre de 1982 y me heredó sus archivos llenos de documentos etnográficos, mismos que recogí en 1983. Fue siempre una anfitriona espléndida, aunque después de su muerte me enteré - por una carta enviada a Foster- que sentía que mis visitas tendían a prolongarse demasiado y a veces impedían que avanzara en los estudios y proyectos arqueológicos y etnográficos que no había terminado. Por supuesto, ella nunca supo que yo tenía indicaciones explícitas de Foster de visitar a "Izzy" — como la llamaba - cada vez que pudiera, asegurarme de que estaba bien y 
atender cualquier necesidad que tuviera relacionada con los Estados Unidos.

\section{EL ARCHIVO ETNOGRÁFICO DE ISABEL KELLY}

Durante una visita a su casa en Tepepan hacia finales de la década de 1970, pedí a Isabel Kelly que pensara en la posterior disposición de su magnífica biblioteca y abundantes materiales etnográficos - no tenía que preocuparse de las colecciones arqueológicas, pues estaban en calidad de préstamo del Instituto Nacional de Antropología e Historia (INAH), a donde serían devueltas cuando ya no las ocupara-. Más tarde, me entregó duplicados de todos sus apuntes de campo, incluida la extensa serie de los totonacos de Tajín. Además, acordó donar su colección de cerámica de Sayula a la Fundación Banamex, y sus libros y revistas al Instituto de Investigaciones Antropológicas de la Universidad Nacional Autónoma de México (IIA-UNAM). Al final, decidió - sin haberme consultado- estipular en su testamento que todos sus materiales etnográficos pasaran a mis manos, incluidos sus diarios de campo, hojas censales, fotografías con negativos, películas, reimpresiones y correspondencia, que abarcaban los proyectos con los miwok de la costa norte de California, con los paiute del sur de la Gran Cuenca/Desierto del Suroeste y con los totonacos, entre otros. Logré transportar ese rico y abundante acervo de regreso a Dallas en mi coche en septiembre de 1983, después del Congreso de la Asociación de Estudios Latinoamericanos, celebrado ese año en la ciudad de México. Con la ayuda de unos estudiantes de posgrado y el apoyo de pequeñas becas de la Universidad y de la Fundación Wenner-Gren para la Investigación Antropológica, elaboramos un inventario de los archivos de Isabel Kelly (Kemper y Marcucci, 1989), antes de depositarlos en la Biblioteca DeGolyer para Colecciones Especiales de la SMU, para asegurar que estuvieran resguardados y a la vez disponibles para cualquier académico que se interesara en ellos. Durante las décadas de 1980 y 1990 seguí trabajando en lo que se conocía como el "archivo Kelly" con otros académicos invitados. Esos estudios intensivos llegaron a despertar mi interés profundo en la participación de académicos estadounidenses en la antropología mexicana en el periodo de 1920 a 1950. La correspondencia de Kelly fue invaluable para esa investigación, sobre todo la que intercambió con Foster. El fruto de ese proyecto fue un importante estudio que apareció primero en inglés (Kemper, 1985) y luego fue traducido al español (Kemper, 1993).

\section{ISABEL KELLY Y RALPH L. BEALS}

Isabel Kelly entró una vez más en mis investigaciones sobre el desarrollo de la antropología en México cuando recibí la invitación de escribir -en coautoría con Catherine Fowler, de la Universidad de Nevada en Reno- un artículo biográfico sobre ella contribuido de manera importante al estudio de la región occidente de Estados Unidos. En esa época también recibí una comunicación de El Colegio de Sinaloa en que se me solicitaba colaborar en la edición de dos tomos en español basados en una obra que Isabel Kelly había escrito en inglés hacia los años de 1940, y que discurría sobre la arqueología del occidente mexicano. Sugerí la idea de traducir el artículo de Fowler-Kemper sobre Kelly — con algunas modificaciones- e incluirlo como la "Introducción" de esos dos estudios arqueológicos. La propuesta fue aceptada y nuestra "Introducción" apareció publicada poco después (Fowler y Kemper, 2008).

A esa experiencia siguió una segunda oportunidad para colaborar con los antropólogos de El Colegio de Sinaloa. Me pidieron que preparara la "Introducción" (Kemper, 2011) a los dos tomos de la obra etnográfica y etnohistórica que publicara en los años treinta y cuarenta del siglo xx Ralph L. Beals, un estudiante 
de Alfred Louis Kroeber en la Universidad de California en Berkeley a finales de los años veinte del siglo pasado, la misma época en que Isabel Kelly estuvo allí. Para elaborar el artículo sobre el trabajo de Beals, viajé al Archivo Nacional de Antropología -NAA, por sus siglas en inglés, ahora ubicado en las afueras de Washington, D. C.--, donde examiné durante varios días el contenido de las más de 50 cajas que constituían el archivo de Beals. Además, revisé con cuidado el extenso archivo del Instituto de Antropología Social de la Smithsonian Institution -ISA, por sus siglas en inglés - bajo cuyos auspicios los Beals, Kelly y Foster trabajaron en un programa dirigido por otro exestudiante de Kroeber, Julian Steward.

\section{ISABEL KELLY Y ÁNGEL PALERM: EL PROYECTO TAJÍN}

Durante los dos años siguientes, conforme llegaban de documentos que había pedido al NAA, descubrí que Palerm también había sido una figura importante en el programa dirigido conjuntamente por el ISA y la ENAH entre 1945 y 1951. A través de aquel programa, académicos estadounidenses fueron invitados a dar cátedras en antropología, lingüística y geografía en el contexto de una iniciativa de enseñanza y capacitación en el trabajo de campo de la ENAH. Los estudiantes incluidos en ese programa recibieron apoyo económico de ambas instituciones. Encontré la primera mención de Ángel Palerm en la correspondencia entre Kelly y Foster en el ISA hacia el final de una larga carta fechada el 1 de febrero de 1948, un par de días antes de que ella saliera a Veracruz para iniciar la segunda temporada de trabajo de campo en El Tajín. Kelly escribió a Foster:

El penúltimo pendiente concierne el anuncio de don Pablo [Martínez del Río, director del INAH] ayer - no, el sábado - al efecto de que había desenterrado a otro candidato para el [trabajo de] campo. Por un lado es una buena noticia, aunque no pude contactar al solicitante ese fin de semana y se supone que debo entrevistarlo mañana. Si va [con nosotros], tendremos que comprar más equipo: catre, colchón, trastes, cubiertos, etc. A decir verdad, la descripción no suena así como muy súper. Es catalán (pero muy quieto y humilde), no ha tomado un solo curso de antropología, pues estudia historia en la universidad. Además, está casado con varios hijos y el problema de mantener a su familia no será un asunto menor. No estoy por rechazar a nadie en estos días sólo porque no esté capacitado, por lo mismo estaba reacia a llevar a Cristina [Álvarez], pero ella resultó excelente. Si Palerma [sic], como lo llaman, parece interesado, quizá lo lleve por un mes de prueba, y si muestra potencial, tal vez lo convenzamos de dejar la historia por la antropología.

El día siguiente, 2 de febrero de 1948, Kelly escribió nuevamente a Foster:

Entrevisté a Palerm (no Palerma) esta mañana. Parece de lo mejor. Tranquilo, casi tímido en su forma de ser, pero claramente inteligente, interesado y bien leído. Está a punto de recibir su licenciatura en historia, pero no quiere continuar en ese campo por los pleitos entre historiadores (parece ser una persona "pacífica", que es muy bueno). Me cayó muy bien en lo personal y sospecho que es bastante listo, quizá llegue a ser la gran esperanza blanca local. Su elección de la etnología fue propia, pues está relacionada con la historia, pero es [a la vez] distinta de ella. Parecía calladamente entusiasta respecto del [trabajo de] campo y planea acompañarnos durante al menos un mes.

Sin embargo, como ya había comentado, hay problemas "económicos", porque está casado y tiene hijos. Don Pablo me dijo en confianza que trataría de conseguir fondos para que la familia pueda sobrevivir mientras su sostén esté en el campo, pero me pidió que no hiciera ningún compromiso al respecto. Entonces, le indiqué a Palerm que debía ver a don Pablo de inmediato para arreglar todo de manera definitiva... Tal vez te interese saber que don Pablo estuvo dispuesto a contribuir 500 pesos al mes para que Palerm pudiera ir... Un gesto bastante magnánimo y una cooperación considerable. Espero que todo funcione, Palerm tiene ideas (preguntó por la posibilidad de administrar una nueva prueba psicológica, que yo desconozco por completo) y creo que 
tal vez resulte un elemento fuerte. Es más maduro que los otros estudiantes y, al parecer, tiene muy buenos antecedentes académicos. ¿Verdad que sería buenísimo si lográramos convertirlo a la etnología?

La historia de la participación de Ángel Palerm en el segundo periodo de trabajo de campo en el Proyecto Tajín continuó más tarde esa misma semana, cuando Kelly escribió una carta a George Foster el 5 de febrero:

Vi ayer a don Pablo y todo está arreglado con Palerm, recibirá 500 pesos al mes de parte del Instituto, lo cual es realmente generoso. Irá por un mes de prueba y pienso que va a funcionar muy bien, muestra más potencial que casi cualquier otro que he visto hasta ahora.

Foster contestó seis días después, el 11 de febrero:

El nuevo ayudante de campo suena muy prometedor. Realmente sería muy bueno encontrar una promesa caliente allí en México para una carrera que durara toda la vida. Sin embargo, un estudiante con varios hijos no suele ser el mejor prospecto. [Pero] parece que don Pablo está haciendo todo lo posible para complacerlo.

El 18 de ese mes, el equipo completo de estudiantes se instaló con Kelly y su asistente, conocido como Chema, en la casa de campo. En su informe a Foster escribió:

Estoy encantada con ese "caballo negro" de don Pablo, Palerm. Es tranquilo y muy introvertido, [pero] más maduro que los otros $y$, sin duda, cuenta con una formación básica infinitamente mejor. Los primeros dos días se me figuraba como un buen "filósofo de sillón" y dudaba mucho de que fuera a valer mucho como investigador en el campo. Empero, floreció a lo largo de la semana y ahora se mueve entre la gente con bastante facilidad. Es algo lento y metódico, nada llamativo (gracias a Dios), pero ha generado varias excelentes sugerencias por su cuenta respecto de nuevas líneas de investigación. Aparte sabe algo de agrimensura y estoy contando con él

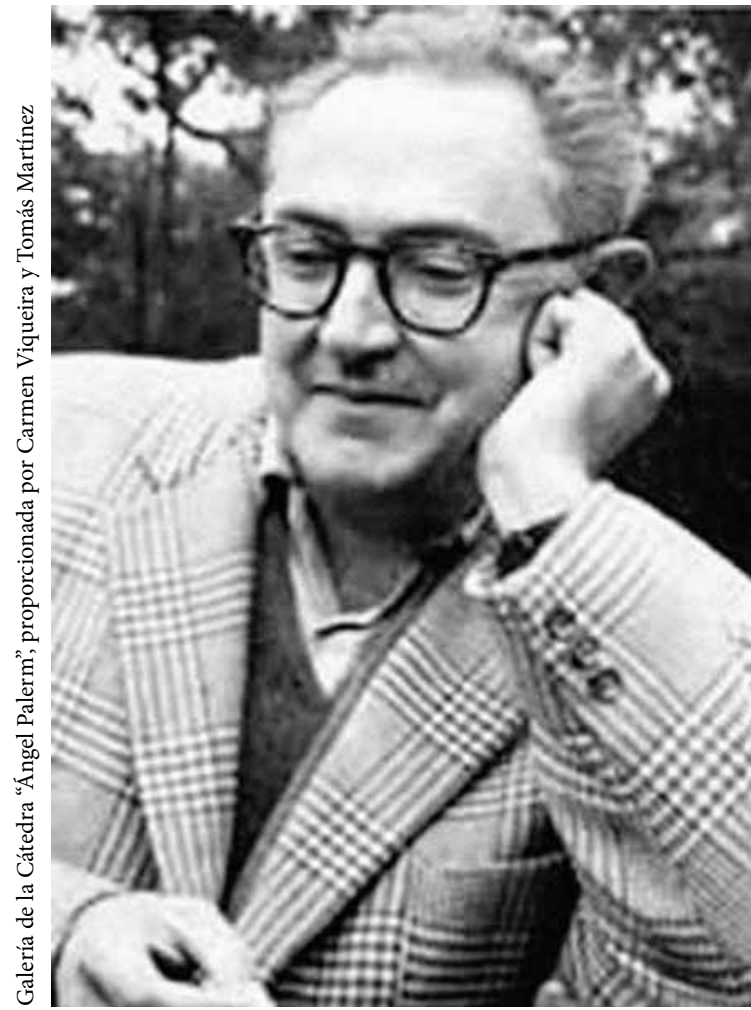

Ángel Palerm.

para terminar el mapa del fondo legal y para corregir algo del trabajo mal hecho de su compañero, el ciudadano Lorenzo [¿apellido?]. Acabo de escribir a don Pablo para expresar mi interés en conservar a Palerm por lo que queda de la temporada.

En su carta del 11 de abril de 1948, escrita desde la estación de campo en Tajín, Kelly comentó:

Palerm sigue siendo una verdadera joya... Ángel ya tiene muchísimos cuates a pesar de su acento español y su tipo físico algo divergente. Ha jugado a la pelota maravillosamente con las autoridades municipales y no pudiéramos tener una relación más chida con ellas. Hasta nos mandan todas las "actas" oficiales, así como por rutina. Trajimos mesas grandes y Ángel está trazando el fondo legal con la asistencia de unos seis faeneros.

También ha hecho todos los arreglos para aplicar unas pruebas psicológicas a algunos escolares: la 
TAT y la Rorschach. Yo estaba bastante aprensiva [al respecto], especialmente después de ver el producto TAT por primera vez... Escribí a Cora [DuBois, excompañera de clase de Kelly en Berkeley y reconocida como experta en el novedoso campo de la antropología psicológica] para preguntarle si no pensaba que haríamos más mal que bien. [Pero] parece que dio su bendición, al menos respecto del TAT, así que le dije a Palerm que lo intentara.

Posteriormente, el 18 de abril, Kelly respondió a una carta de George Foster acerca de la situación presupuestaria para el año fiscal que se aproximaba:

Lo del presupuesto no va a ser fácil. Voy a necesitar, de ser posible, un corto periodo de campo para llenar algunas lagunas. Aparte, me gustaría mucho contratar a Palerm como auxiliar para que me eche la mano en la elaboración del reporte. Ya planteé esta propuesta tentativa a don Pablo, preguntándole si sería posible que la Escuela autorizara un pago de, digamos, 200 pesos al mes, del resto que quedó [del presupuesto] del año pasado. Calculo que tendré unos 2000 de los 6000 pesos de sobra, al menos. Palerm tiene esposa y dos hijos que mantener. La Escuela planea darle una beca de 200 pesos. Si la Escuela y el Smithsonian pudieran contribuir con otros 200 pesos cada uno al mes, [Palerm] podría mantener a su familia y dedicarse de tiempo completo a asuntos académicos. De no ser así, tendrá que volver a su empleo anterior: $j e n$ una imprenta o a un puesto de cereales en la Merced!... Podría seguir con los registros del censo federal, esos datos también tienen que ser trabajados de nuevo - calcular porcentajes, graficar, etc.-. Aparte, podría trabajar con los archivos - buscando referencias históricas, registros de tierras, etc.-, además de ayudarme enormemente en la organización preliminar de los detalles de varios capítulos. Sería una bendición para mí - y le ayudaría también a él- participar en la mecánica de organizar un reporte extenso.

No cabe la menor duda -es, y por mucho- la mejor promesa como futuro etnólogo en México, [por su] visión realmente profesional. Es más maduro que la norma, tiene una buena familia y buenos antecedentes culturales. Su cabeza es buena y percibe problemas e implicaciones mayores, así como los detalles. Es minucioso y diligente. Sus fichas son un deleite. Persevera en una serie de temas relacionados hasta sentir que los tiene muy bien dominados, nunca deja enredos o cabos sueltos. Es pacífico y pensativo, pero se lleva de maravillas con los informantes. Es casi tan buen diplomático como Gabriel [Ospina, un colombiano que trabajó en el Proyecto Tzintzuntzan con George Foster y participó en la primera temporada de trabajo de campo en Tajín], aunque destaca menos. Tiene a las autoridades municipales comiendo de su mano, incluso nos mandan sus actas oficiales (pleitos de familia, asaltos, trifulcas, etc.). Es una joya, es tantísimo mejor que cualquier otro que he visto en el horizonte local que es patético incluso compararlo con los demás. Pero lo que es más, adora el trabajo, es entusiasta y totalmente abierto a sugerencias. Puedo confiar en que su trabajo siempre será minucioso y consciente (suena como el anuncio de un nuevo automóvil).

El 29 abril de 1948, Foster respondió finalmente a los efusivos comentarios de Isabel Kelly sobre Ángel Palerm:

Tu trabajo de campo suena maravilloso. No sé mucho sobre ese nuevo acercamiento psicológico, pero será interesante ver lo que Palerm puede conseguir. $\mathrm{Y}$ me encanta que por fin se ha descubierto un buen estudiante, no sé por qué eso resulta tan difícil en México.

Más tarde, y tras no recibir comentario alguno de parte de Foster sobre su petición de contratar a Palerm como auxiliar, el 8 de mayo de 1948 Kelly envió una segunda solicitud:

Sólo una nota breve (comparada con mis misivas normales) para preguntarte si estás a favor de contratar a Palerm como auxiliar [al costo de] 200 pesos mensuales. Escribí anteriormente para preguntarte si estarías de acuerdo. Como auxiliar sería utilísimo para elaborar los reportes y pienso que el reto también resultaría benéfico para él. Ahora que el trabajo de campo está a punto de terminar, debe arreglárselas de alguna manera a partir del mes que entra, porque sus viáticos terminarán. Don Pablo parece estar bastante [seguro] de que el Instituto pueda poner 200 pesos, siempre y cuando tú estés interesado. Pero [me dijo] que quisiera saber definitivamente 
antes de llegar a un arreglo final con [Rubín de la] Borbolla [director de la ENAH].

Luego de recibir la respuesta positiva de Foster, Kelly respondió el 17 de mayo:

Acaba de surgir una traba seria en el arreglo con Palerm. En México, al parecer, la beca estipula que el becario esté al servicio de Borbolla por las mañanas. Ya le dije a don Pablo que en esas circunstancias la participación del Smithsonian quedaría [descartada]. Palerm calcula 550 pesos mensuales como el mínimo para su familia (pero es más allá de mi comprensión cómo su esposa y sus dos pequeños niños pudieran vivir con [esa suma]). Tenemos comprometidos 400 pesos, la mitad del Smithsonian y la otra mitad del Instituto. He escrito para preguntar si el Instituto estaría dispuesto a pagar cien pesos adicionales si yo me comprometo personalmente a completar los 50 restantes. Estimo muchísimo a Palerm, como tú sabes. Es una de las pocas personas con quien podría contar para una inteligente evaluación de antiguas fuentes y archivos. Si no está disponible como ayudante, el reporte contendría pura descripción, con muy poco fondo histórico, material comparativo, etc.

Foster contestó a Kelly rápidamente y en tono positivo el 27 de mayo de 1948:

Respecto de Palerm, espero que logres obtener fondos adicionales del Instituto; sin embargo, no hay razón alguna para que tú pongas el balance de 50 pesos. Ese [gasto] lo puedes incluir legítimamente en tu cuenta de gastos. Cualquier cosa que se puede hacer para mejorar la exhaustividad y calidad del reporte está claramente justificada.

Unos dos meses después, el 28 de julio, Isabel Kelly escribió a Foster para informarle que estaba trabajando duro en el informe sobre Tajín y nuevamente se expresó en tono halagador sobre la contribución de Palerm:

Sigo encantada con Palerm, tiene una mente excelente... muy activa, y tiene sed de aprender. Ha presentado cuatro exámenes en materias a las cuales ni siquiera asistió desde que salió al campo. En dos recibió un 10 , los resultados de las otras dos están pendientes... Estoy segura de que tenemos un verdadero discípulo en Palerm y sé que con más capacitación podrá defenderse con profesionales en cualquier lugar. Bertha [Harris, amiga de Kelly, que trabajaba en la Biblioteca Benjamín Franklin, BBF] lo inscribió en clases de inglés en la BBF y está dedicado a eso, entre otras cosas. Me parece que lo ha hecho bastante bien en su tarea de verificar las historias tempranas, y muy pronto espero ponerlo a [analizar] el censo y los archivos. Es brillante en todos los aspectos salvo los financieros, pues es casi un imbécil en lo referente al dinero, verdaderamente patético.

\section{LOS TOMOS DE HOMENAJE A PALERM}

Ángel Palerm volvió a entrar en mi vida profesional hacia finales de la década de 1980 cuando Susana Glantz empezó a organizar un tomo de homenaje en su honor. Resultó que me escogieron como uno de los pocos académicos en Estados Unidos para escribir una contribución para dicho libro. Mi artículo fue "El desarrollo de los estudios antropológicos sobre la migración mexicana". Al parecer hubo una seria controversia en México sobre la administración del proyecto de homenaje y su posterior publicación. A final de cuentas, consulté con Eric Wolf y, como no deseaba ofender a ninguna de las dos facciones involucradas, accedí a que mi capítulo apareciera en ambas ediciones (Kemper, 1987, 1990).

\section{EL PROYECTO TAJÍN 60 AÑOS DESPUÉS}

Mucho más tarde, en 2009, Elio Masferrer Kan, exestudiante mío de la Ibero, se enteró de que yo tenía los materiales de Kelly y decidimos hacer algo con esa colección. De hecho, y gracias a él, las conexiones antropológicas de Kelly y Palerm con los totonacos en Tajín se mantienen hasta la fecha. A comienzos de 2010, después de visitar Dallas y conocer el archivo de primera mano, Masferrer me 
acompañó a Veracruz en lo que fue mi primer viaje a esa región. Planeamos una presentación en el centro comunitario local con unas láminas preparadas en PowerPoint con imágenes de los archivos de Kelly escaneadas, acompañadas de una versión digital de una corta película sin sonido hecha para captar la tradicional "Danza de los Negritos". Nuestra presentación estaba programada para iniciar a las 5:30 de la tarde, pero a las 5:00 el auditorio del pueblo estaba repletísimo, de manera que empezamos antes de la hora fijada. Fue un gran éxito, en parte porque dos hombres de la localidad, uno en el violín y el otro en la guitarra, amenizaron la exhibición de la película con un magnífico fondo musical en vivo que complementaba a la perfección la imagen de los danzantes en la pantalla. Al terminar, decidimos repetir el espectáculo porque al pedir a los asistentes que se retiraran las docenas de personas que se habían quedado afuera llenaron de nuevo el recinto.

Como resultado de esa iniciativa de Masferrer, empezamos a devolver buena parte de los materiales de Kelly sobre los totonacos a la gente que reside en El Tajín. Desde muchos años atrás, ellos sabían de la existencia de esos papeles, pero no tenían acceso a ellos. Con tecnología moderna logramos escanearlos o duplicarlos -incluidos cientos de fotografías y la famosa película de la "Danza de los Negritos" - para devolverlos a la comunidad donde habían sido recolectados unos 60 años antes. Qué alegría fue regresar a ese pueblo su propia historia y ver a la gente contemplar fotos de sus abuelos que habían fallecido hace mucho o incluso de ellos mismos cuando eran pequeños. Todo el evento se arregló con gran éxito, hasta mereció una amplia cobertura en los periódicos regionales, algo que hubiera deleitado tanto a Isabel Kelly como a Ángel Palerm. Esa experiencia personal en Tajín me dio una nueva perspectiva y un nuevo aprecio por el trabajo que Palerm había desempeñado allí y que posteriormente fue incorporado en su acercamiento a la formación de nuevos estudiantes de antropología.

\section{CRÓNICAS CULTURALES}

En 2011, la Universidad Iberoamericana y el Centro de Investigaciones y Estudios Superiores en Antropología Social (CIESAS) publicaron la traducción al español del libro Chronicling Cultures (Kemper y Peterson, 2002), que incluye relatos de las historias de conocidos proyectos de trabajo de campo a largo plazo, entre ellos el de Tzintzuntzan. Esta nueva edición en español, titulada Crónicas culturales (Kemper y Peterson, 2010), fue facilitada por Marisol Pérez Lizaur, quien formaba parte del Comité de Publicaciones de la Ibero en el periodo en que el texto se presentó para su dictamen. ${ }^{5}$

Una vez más, la impronta de Palerm fue evidente. Si él no hubiera establecido los programas de antropología en la Ibero y en el CIESAS - originalmente, Centro de Investigaciones Superiores (CIs) del INAH-, esas instituciones jamás hubieran publicado Crónicas culturales en coedición. Por eso estoy eternamente agradecido con Ángel Palerm por aquella invitación a participar en el programa de la Ibero en el aeropuerto de Nueva Orleans en 1969, que resultó ser el primer paso de una larga travesía de trabajo de campo y docencia en instituciones mexicanas de antropología. A menudo me pregunto si él imaginó alguna vez las consecuencias que tendría aquel primer, fortuito $-\mathrm{y}$ grato- encuentro $\mathrm{y}$ todo lo que acontecería en los años posteriores.

\section{CONCLUSIÓN}

Por último, no puedo más que reflexionar sobre lo que Isabel Kelly y George Foster hubieran pensado del impacto que tuvieron en la carrera de Ángel Palerm, así como del que él tuvo en la mía. En ese contexto, el 3 de enero de 1949 Kelly escribió a

\footnotetext{
${ }^{5}$ Conocí a Marisol Pérez Lizaur en la década de 1980 cuando escribía con Larissa Adler Lomnitz su libro sobre una familia de la elite en México (Pérez y Adler, 1988).
} 
Foster para decirle: "Palerm es la esperanza blanca para la etnología mexicana". Visto en ese periodo histórico, no fue un comentario racista, sino un reconocimiento de las muchas cualidades especiales que poseía Ángel Palerm, incluido el carisma reflejado en su estilo de liderazgo. Hemos visto ese carisma en todo lo que logró a lo largo de su carrera antropológica, desde su trabajo en la Unión Panamericana a comienzos de la década de 1950, en su docencia en la ENAH a mediados de los años sesenta - truncada por los trágicos eventos de octubre de 1968-, en su papel en la fundación del Instituto de Ciencias Sociales y del Departamento de Antropología de la Universidad Iberoamericana a finales de la misma década, en la creación del CIs-INAH en los años setenta y en todo lo que hizo y produjo hasta su muerte en 1980. Jamás dejó de practicar el carismático liderazgo que lo caracterizaba y en todos esos momentos institucionales de vasta importancia y en su trabajo personal la experiencia del trabajo de campo permaneció en el corazón de lo que ahora es un legado permanente a la antropología.

\section{BIBLIOGRAFÍA}

Adler Lomnitz, Larissa, 1975, Cómo sobreviven los marginados, Siglo XXI, México.

Fowler, Catherine S. y Robert V. Kemper, 2008, "Una vida en el campo: Isabel T. Kelly, 1906-1982”, en Isabel T. Kelly, Excavaciones en Chametla, Sinaloa, Siglo XXI, El Colegio de Sinaloa, México, pp. IX-XLIII.

Kelly, Isabel y Ángel Palerm, 1952, The Tajín Totonac. Part I. History, Subsistence, Shelter, and Technology, Institute of Social Anthropology-Smithsonian Institution, (Publication, núm. 12), Washington, D. C.

Kemper, Robert V., 1985, "From Nationalism to Internationalism: The Development of Mexican Anthropology, 1934-1946”, en June Helm (ed.), Social Contexts of American Ethnology, 1940-1984, American Ethnological Society, Washington, D. C., pp. 139-156.
1987, "Desarrollo de los estudios antropológicos sobre la migración mexicana”, en Susana Glantz (comp.), La heterodoxia recuperada, en torno a Ángel Palerm, Fondo de Cultura Económica, México, pp. 477-499.

—, 1990, "Desarrollo de los estudios antropológicos sobre la migración mexicana”, en Modesto Suárez (comp.), Historia, antropología y política, vol. II, Alianza Editorial Mexicana, México, pp. 9-32.

, 1993, "Del nacionalismo al internacionalismo: el desarrollo de la antropología mexicana, 1934-1946", en Ralph L. Beals y Robert V. Kemper, Dos lecturas de la antropología mexicana, Laboratorio de Antropología-Universidad de Guadalajara (Cuadernos de Antropología), Guadalajara.

, 1996, "La comida en Tzintzuntzan, Michoacán: tradiciones y transformaciones", en Janet Long (ed.), Conquista y comida: consecuencias del encuentro de dos mundos, Universidad Nacional Autónoma de México, México, pp. 365-395.

_, 2011, "Ralph L. Beals: investigaciones antropológicas en México", en Ralph L. Beals, Obras, vol. I: Etnohistoria del noroeste, Siglo XXI, El Colegio de Sinaloa, Instituto Nacional de Antropología e Historia, México.

y John Marcucci, 1989, “The Isabel T. Kelly Ethnographic Archive: A Descriptive Guide”, en Yólotl González (coord.), Homenaje a Isabel Kelly, Instituto Nacional de Antropología e Historia (Colección Científica, núm. 179), México, pp. 59-70.

- y Anya Peterson Royce, 2002, Chronicling Cultures: Long Term Field Work in Anthropology, Alta Mira Press, Walnut Creek.

— 2010, Crónicas culturales, Universidad Iberoamericana, Centro de Investigaciones y Estudios Superiores en Antropología Social, México.

Long de Solís, Janet, 1986, Capsicum y cultura: la historia del chilli, Fondo de Cultura Económica, México.

Masferrer Kan, Elio, 2003, "Los totonacos", en Elio Masferrer et al. (coords.), Etnografía del estado de Puebla. Puebla norte, 3 t., Dirección de Literatura, Ediciones y Bibliotecas-Secretaría de Cultura del Estado de Puebla, Puebla, pp. 178-187.

Pérez Lizaur, Marisol y Larissa Adler Lomnitz, 1988, A Mexican Elite Family, 1820-1980: Kinship, Class, Culture, Princeton University Press, Princeton. 